\title{
Comparison of clinical outcomes of expansive open-door laminoplasty with unilateral or bilateral fixation and fusion for treating cervical spondylotic myelopathy: a multi-center prospective study
}

Nan Su', Qi Fei ${ }^{1}$, Bing-Qiang Wang ${ }^{1}$, Nan Kang ${ }^{2}$, Qing-Ming Zhang ${ }^{3}$, He-Hu Tang ${ }^{4}$, Dong Li ${ }^{1}$, Jin-Jun Li ${ }^{1}$ and Yong Yang ${ }^{1 *}$

\begin{abstract}
Background: The present study evaluated the clinical outcomes and safety of expansive open-door laminoplasty, when securing with C4 - C6 lateral mass screw and fusion.

Methods: A total of 110 patients with cervical spondylotic myelopathy (CSM) were enrolled. There were 88 male and 22 female, with mean age at $60.55 \pm 10.95$ years. All of the patients underwent expansive open-door laminoplasty with unilateral or bilateral C4-6 lateral mass screws fixation and fusion. Clinical data, including age, gender, operation-related information, pre- and post-operation Japanese Orthopedic Association (JOA) scores, and cervical curvatures were collected.

Results: The mean follow-up time of the cohort was $13.61 \pm 9.53$ months. Among the 110 patients, 33 of them were allocated to Unilateral group, and 77 of them were in Bilateral group. The mean JOA score of the 110 patients before surgery was $10.07 \pm 2.39$, and the score was improved significantly to $12.85 \pm 2.45$ after surgery. There were no reported cases of neurological deterioration or symptom worsening. Patients in both the Unilateral group and Bilateral groups had significant improvement of JOA scores. Among all patients, the most frequently observed complications were axial symptoms $(n=7)$. The average preoperative cervical curvature among all patients was $15.17 \pm 5.26$, and the post-surgery curvature was $14.41 \pm 4.29$. Similar observations were found between Unilateral and Bilateral groups.
\end{abstract}

Conclusion: The modified surgical approach provided satisfactory clinical outcome in patients with CSM. The unilateral and bilateral fixation appeared to provide similar outcomes, in terms of cervical curvature maintenance and improvement of clinical symptoms. However, the examination of the exact differences between the two fixation methods await further biomechanical studies.

Keywords: Cervical spondylotic myelopathy, Open-door laminoplasty, Fixation, Fusion

\footnotetext{
* Correspondence: spineyang@126.com

1Department of Orthopaedics, Beijing Friendship Hospital, No. 95 Yongan

Road, Xicheng District, Beijing 100050, China

Full list of author information is available at the end of the article
}

C The Author(s). 2019 Open Access This article is distributed under the terms of the Creative Commons Attribution 4.0 International License (http://creativecommons.org/licenses/by/4.0/), which permits unrestricted use, distribution, and reproduction in any medium, provided you give appropriate credit to the original author(s) and the source, provide a link to the Creative Commons license, and indicate if changes were made. The Creative Commons Public Domain Dedication waiver (http://creativecommons.org/publicdomain/zero/1.0/) applies to the data made available in this article, unless otherwise stated. 


\section{Introduction}

Cervical spondylotic myelopathy (CSM) is a degenerative spinal disease that is most commonly found in people aged 55 years or older [1]. CSM can be caused by a direct compression of the cervical spinal cord or surrounding blood vessels. The symptoms of CSM ranged from numbness or weakness in upper extremity, loss of coordination, neck pain to quadriparesis or sphincter dysfunction. It was estimated that the CMS-related hospitalization was 4.04 per 100,000 person-years, and the number of CMS patients receiving surgical treatment has been increasing [2, 3]. In addition to the acquired degenerative processes, developmental canal stenosis (DCS) is a well-recognized predisposing factor for CSM development. Study showed that patients with CSM have a high incidence of DCS [4]. The congenital stenosis can be defined using X-ray images when the ratio of canal diameter to vertebral body diameter is less than 0.8 [5].

Surgery is often considered for treating CSM, aiming to decompress the cord with an expansion of the spinal canal. An anterior surgical approach is preferred when one to two levels are involved, while a posterior approach is considered when three or more levels are involved or when DCS is presence [1]. To perform laminoplasty, a satisfactory cervical lordosis is required for successful operation, as the cord may not drift posteriorly from the lesion with cervical kyphosis. However, there were some disadvantages of the posterior approach; for example, the lordosis angle may lost between $6.7^{\circ}-11.7^{\circ}$, or up to $35 \%[6,7]$. In order to prevent poor curvature of the cervical spine after surgery, many researchers modified the traditional surgical approach by persevering the nuchae muscle attachment [8], preserving or repairing the $C 2$ semispinalis cervics [9], or preserving C7 spinous processes [10]. Some researchers also suggested the performance of C3-6 laminoplasty, instead of C3-7 [10,11]. Nonetheless, the above surgical approaches are technically more challenge. The addition of fixation, such as Twinfix suture anchors [12] or titanium miniplates [13, 14], were used to avoid door closure.

Our institute has modified the posterior surgical approach, in which the expansive open-door laminoplasty was performed with the addition of short segment (C46) lateral mass screw fixation and fusion. This surgical approach achieved satisfactory clinical outcome in our previous single-center retrospective study [15]. To validate this surgical approach in different clinical settings, we performed a multi-center study. In this study, we also evaluated if there were any differences in efficacy between the unilateral and bilateral fixation. The clinical outcome and surgical related complications were reported here.

\section{Patients and methods}

\section{Patient characteristics}

This was a multi-center study, with a total of 110 patients enrolled. Four medical centers in China participated in this study, including Beijing Friendship hospital, Beijing Xuanwu hospital, Beijing Chaoyang hospital and Beijing Boai hospital. Ethic approvals were received from all institutes participated in this study. The patients were diagnosed with cervical spondylotic myelopathy (CSM) in combination with developmental cervical spinal canal stenosis between May 2014 and April 2017. CSM refers to a group of clinical symptoms that resulted from the compression of important structures around the cervical spine (e.g. nerve root, vertebral artery, sympathetic nerve). It is often caused by the degeneration of cervical intervertebral disc and surrounding bone and soft tissue. All of the patients fulfilled the eligibility criteria and provided informed consent. The main inclusion criteria included: (1) Diagnosis of CSM with developmental narrowing of the cervical spinal canal. Patients also presented symptoms of cervical spinal cord compression; (2) age 40 or above; (3) the stenosis spanned at three or more cervical segments. The main exclusion criteria included: (1) medical history of cervical spine fractures, dislocation, deformities, tumors, tuberculosis or other infection; (2) concomitant neurological diseases leading to pyramidal tract syndrome; (3) preoperative cervical kyphosis with C2-7 Cobb's angle $>13^{\circ}$; (4) presence of severe osteoporosis or autoimmune diseases (e.g. rheumatoid arthritis, ankylosing spondylitis); (5) incomplete imaging data.

The functional status of patients with CSM was evaluated by Japanese Orthopaedic Association (JOA) score. Flexion-extension X-ray, cervical MRI, and CT examination were performed before surgery. All patients underwent posterior cervical expansive open-door laminoplasty, with short-segment ( $\mathrm{C} 4$ to $\mathrm{C} 6)$ unilateral or bilateral lateral mass screw and fusion. Patients had follow-up visits at 1-month, 3-month, 6-months, and 12-month post-surgery. JOA score assessment and X-ray imaging were performed during the follow-up visits.

\section{Surgical technique}

Patients were not randomly assigned to unilateral or bilateral fixation, but in some cases, operators would perform bilateral fixation because of the patients' condition (e.g. preoperative lordosis, poor cervical curvature, osteoporosis). The patient received general anesthesia and was placed in prone position on an operating table. The patient's head was stabilized with a skull clamp. A posterior longitudinal incision was made in the midline of the neck to expose the C3-7 spinous process. Drilled holes were made at the lateral side of C4-6. Then, the interspinous ligaments at $\mathrm{C} 2-3$ and $\mathrm{C} 7-\mathrm{T} 1$ were split, 
and the spinous processes were removed (with approximately $3 \mathrm{~mm}$ left). A hole in the base of the spinous process was made, and a needle was used to bring a silk suture thread through the hole. The outer cortex at the right side of C3-7 lamina base was removed using a burr, creating a door of about $3 \mathrm{~mm}$ width. The cortex at the left side of C3-7 lamina was removed to create a door of about 1.2 to $1.5 \mathrm{~cm}$ width. For patients in Unilateral group, three pairs of lateral mass screws were fixed at the right side of C4-6. For patients in Bilateral group, three pairs of lateral mass screws were fixed at C4-6 bilaterally. The resected spinous process was made into a matchstick-like autograft and was fixed securely in the laminar opening. The silk suture thread was tied to the screw to prevent closure of the laminoplasty. To close the wound, normal saline was used for copious irrigation of the wound. Retractors were removed and hemostasis was achieved. A standard layered closure was performed.

\section{Postoperative management}

The drainage tube was removed $48 \mathrm{~h}$ after surgery, and antibiotics were administrated for 2 days. Methylprednisolone was used to reduce edema of spinal nerve roots ( $80 \mathrm{mg}$ for 3 days). Low molecular weight heparin was used to prevent venous thromboembolism. Mobilization, and physical therapy started with the protection of Philadelphia neck collar after the drainage was removed. AP and lateral X-rays were obtained prior to patient discharge. Patients could discontinue the use of their collar after 3 months.

\section{Data collection and analyses}

Complete medical records, including age, gender, duration of hospital stay, volume of blood loss, operation time, and intraoperative complications were collected. Preoperative and postoperative JOA scores were obtained (full score $=17$ points). The postoperative improvement was calculated as previously described: (follow-up JOA score - preoperative JOA score)/(17 - preoperative JOA score) $\times 100 \%$ [15]. The X-ray images were analyzed, and cervical spine sagittal sequence (Cobb's angle between $\mathrm{C} 2$ lateral endplate and C7 endplate) were obtained. All surgical related complications (e.g. screw loosening) were recorded during the analysis of X-ray images.

\section{Statistical analyses}

Qualitative data were presented as percentage (\%), and the measurement data were presented as mean \pm standard deviation. For data that were normally distributed, Student's t-test was used, while Wilcoxon two sample test was used for data that were not normally distributed. The pre- and post-operative JOA scores were analysed by paired t-test or Wilcoxon signed rank test. The post-operative JOA scores and curvatures between groups were compared using repeated measures ANOVA. All statistical analyses were performed using SAS9.3. Statistical significance was considered when $p<0.5$.

\section{Results}

One hundred ten patients were enrolled in this study, and 33 of them were allocated to Unilateral group and 77 of them were in Bilateral group. There were 88 male and 22 female, with mean age at $60.55 \pm 10.95$ years. The mean BMI was $25.34 \pm 2.86 \mathrm{~kg} / \mathrm{m}^{2}$. The mean follow-up time of the cohort was $13.61 \pm 9.53$ months, and a total of 32 patients had segmental instability. No significant differences were found in these characteristics between the Unilateral group and Bilateral group (Table 1).

The intra- and post-operative conditions of patients were summarized in Table 2. The mean operation time was $150.58 \pm 35.26 \mathrm{~min}$, and the mean volume of blood loss was $331.37 \pm 152.34 \mathrm{~mL}$. The total drainage volume was $226.71 \pm 130.01 \mathrm{~mL}$. Patients stayed in hospital for approximately 17-18 days. Two cases of fat liquefaction were observed after surgery: one in the Unilateral group and one in the Bilateral group. These patients needed a

Table 1 Clinical characteristics of patients

\begin{tabular}{llll}
\hline Parameters & Unilateral $n=33$ & Bilateral $n=77$ & All patients \\
\hline Gender, $\mathrm{n}(\%)$ & & & \\
$\quad$ Male & $24(72.73)$ & $64(83.12)$ & $88(80.00)$ \\
$\quad$ Female & $9(27.27)$ & $13(16.88)$ & $22(20.00)$ \\
Age (yr), mean \pm s.d. & $58.73 \pm 10.59$ & $61.32 \pm 11.07$ & $60.55 \pm 10.95$ \\
$\quad$ Minimum-Maximum & $40-80$ & $40-81$ & $40-81$ \\
BMI (kg/m ${ }^{2}$ ), mean \pm s.d. & $25.87 \pm 2.89$ & $25.09 \pm 2.84$ & $25.34 \pm 2.86$ \\
$\quad$ Minimum-Maximum & $20.7-35.49$ & $18.37-32.87$ & $18.37-35.49$ \\
Follow-up time (month), mean \pm s.d. & $13.00 \pm 7.523-36$ & $13.87 \pm 10.303-36$ & $13.61 \pm 9.533-36$ \\
Minimum-Maximum & & & 0.225 \\
$\quad$ Segmental instability, $\mathrm{n}$ (\%) & $10(30.30)$ & $22(28.57)$ & $32(29.09)$ \\
\hline
\end{tabular}


Table 2 Intraoperative and postoperative conditions

\begin{tabular}{|c|c|c|c|c|}
\hline Parameters & Unilateral $n=33$ & Bilateral $n=77$ & All patients & $p$ \\
\hline Operation time (min), mean \pm s.d. & $141.82 \pm 30.51$ & $154.34 \pm 36.65$ & $150.58 \pm 35.26$ & 0.113 \\
\hline Intraoperative bleeding $(\mathrm{ml})$, mean \pm s.d. & $333.06 \pm 144.73$ & $330.65 \pm 156.4$ & $331.37 \pm 152.34$ & 0.937 \\
\hline Total drainage $(\mathrm{ml})$, mean \pm s.d. & $197.97 \pm 89.22$ & $239.03 \pm 142.75$ & $226.71 \pm 130.01$ & 0.085 \\
\hline Duration of hospital stay (day), mean \pm s.d. & $18.06 \pm 7.40$ & $17.75 \pm 6.48$ & $17.85 \pm 6.74$ & 0.768 \\
\hline Postoperative fat liquefaction, n (\%) & $1(3.03)$ & $1(1.30)$ & $2(1.82)$ & 0.512 \\
\hline \multicolumn{5}{|l|}{ Bone graft fusion, n (\%) } \\
\hline Completely fused & $27(84.38)$ & $76(98.70)$ & $103(94.50)$ & 0.008 \\
\hline Partially fused & $5(15.63)$ & $1(1.30)$ & $6(5.50)$ & \\
\hline
\end{tabular}

longer time for wound healing, but no infection was observed. The above intra- and post-operative conditions were similar between the two groups; no significant differences were found. Overall, most of the patients had the bone autograft completely fused.

Complications developed during the follow-up period were recorded (Table 3 ). There were no significant differences between Unilateral and Bilateral groups. Among all patients, the most frequently observed complications were axial symptoms $(n=7)$. The axial symptoms were mainly presented as pain or discomfort in neck and shoulders. Majority of the patients recovered within a year; some still experienced the discomfort, but their daily activates were not affected. There were 4 patients reported C5 palsy. C5 palsy was defined as the deterioration in power of the deltoid muscle by at least one grade. It may accompany with deterioration in power of the biceps, but not the deterioration in power of other upper arm muscles. Numbness or pain may also be presented in muscles innervated by $\mathrm{C} 5$. All patients with $\mathrm{C} 5$ palsy recovered within a year after surgery. Lastly, one case of caudal adjacent segment degeneration (ASD) and one case of internal fixation loosening were reported. ASD was defined as the presence of bone hyperplasia, intervertebral disc herniation, ligament hypertrophy, or cervical segment instability in adjacent segments. Overall, the complication rate was low.

The neurological recovery was measured by JOA score. The mean JOA score of the 110 patients before surgery was $10.07 \pm 2.39$, and the score was significantly improved to
$12.85 \pm 2.45$ after surgery. The mean score increased to $14.66 \pm 1.86$ at 3 months after surgery $(p<0.05)$. There were no reported cases of neurological deterioration or symptom worsening. Patients in both of the Unilateral group and Bilateral groups had significant improvement of JOA scores at different time points (before discharge, 3-, 6-, 12-, and 24month post-surgery), when compared to the baseline. No significant differences were found in JOA score between Unilateral group and Bilateral group (Table 4).

The X-ray images were analyzed to examine the cervical curvature (C2-7 Cobb's angle) of patients. The average preoperative cervical curvature among all patients was $15.17 \pm 5.26$, and the post-surgery curvature was $14.41 \pm 4.29$ (Table 5). There was no significant difference between the pre- and post-surgery curvature. Similar observations were found in Unilateral and Bilateral groups. The Cobb's angle was increased significantly at 6-, 12-, and 24-month post-surgery; however, it was noteworthy to mention that only a small portion of patients ( $n=11$ at 24-month) had X-ray images available for the analyses. Images of typical cases from Unilateral and Bilateral groups before and after surgery were shown in Figs. 1 and 2.

\section{Discussion}

The present study investigated the modified surgical approach for treatment of patients with CSM. We improved the traditional single-door decompression procedure by including the C4-6 lateral mass screw fixation and fusion. The use of lateral screws could maintain or in some cases

Table 3 Complications after discharge from hospital

\begin{tabular}{|c|c|c|c|c|}
\hline Complications during follow-up period & Unilateral $n=33$ & Bilateral $n=77$ & All patients & $p$ \\
\hline Segmental instability & $1(3.03)$ & $4(5.19)$ & $5(4.55)$ & 1.000 \\
\hline C5 palsy & $0(0.00)$ & $4(5.19)$ & $4(3.64)$ & 0.314 \\
\hline Axial symptoms & $4(12.12)$ & $3(3.90)$ & $7(6.36)$ & 0.194 \\
\hline Caudal ASD & $0(0.00)$ & $1(1.30)$ & $1(0.91)$ & 1.000 \\
\hline Loosening of internal fixation & $0(0.00)$ & $1(1.30)$ & $1(0.91)$ & 1.000 \\
\hline
\end{tabular}

$A S D$ adjacent segment degeneration 
Table 4 Changes of JOA score before and after surgery

\begin{tabular}{|c|c|c|c|c|c|c|c|}
\hline & Uni & & Bila & & All $p$ & & $p$ \\
\hline & $n$ & JOA score & $n$ & JOA score & $\mathrm{n}$ & JOA score & \\
\hline Before surgery & 33 & $9.94 \pm 2.34$ & 77 & $10.13 \pm 2.42$ & 110 & $10.07 \pm 2.39$ & 0.683 \\
\hline Before discharge & 33 & $12.73 \pm 2.45^{a}$ & 77 & $12.91 \pm 2.46^{b}$ & 110 & $12.85 \pm 2.45^{c}$ & 0.687 \\
\hline 3 months post-surgery & 33 & $15.12 \pm 1.63^{a}$ & 77 & $14.47 \pm 1.93^{b}$ & 110 & $14.66 \pm 1.86^{c}$ & 0.571 \\
\hline 6 months post-surgery & 9 & $15.56 \pm 0.88^{a}$ & 18 & $15.39 \pm 1.09^{b}$ & 27 & $15.44 \pm 1.01^{c}$ & 0.712 \\
\hline 12 months post-surgery & 16 & $14.88 \pm 2.16^{a}$ & 32 & $15.28 \pm 1.25^{b}$ & 48 & $15.15 \pm 1.6^{c}$ & 0.497 \\
\hline 24 months post-surgery & 6 & $15.17 \pm 0.75^{a}$ & 8 & $14 \pm 2.51^{b}$ & 14 & $14.5 \pm 1.99^{c}$ & 0.081 \\
\hline
\end{tabular}

${ }^{a}$ compared to Unilateral before surgery, $p<0.05 ;{ }^{b}$ compared to Bilateral before surgery, $p<0.05 ;{ }^{c}$ compared to All patients before surgery, $p<0.05$

correct the cervical lordosis. Also, the use of suture and bone autograft could prevent the fixation failure and to keep the door maintained in the open position. In our previous single-center retrospective study, this modified surgical approach promoted neurological recovery of patients: the JOA score increased from $9.14 \pm 2.25$ before surgery to $15.31 \pm 1.73$ after surgery, and the clinical symptoms were also significantly improved [15]. In this multi-center prospective study, the use of the modified surgical approach also provided satisfactory clinical outcome, indicating the reproducibility and effectiveness of the surgical method in treating CMS.

There has been controversy on the application of internal fixation for laminoplasty. Hyun et al. reported that the mean range of motion after cervical laminoplasty (including miniplate fixation) decreased by $10.1^{\circ} \pm 9.5^{\circ}$ (31.66\%) [16]. Another study also reported that the range of motion decreased 30.5 , and $10.6 \%$ of patients experienced kyphosis after laminoplasty [17]. In view of these, we modified the single-door laminoplasty with the addition of short-segment C4-6 lateral fixation. This surgical approach retained the range of motion of the upper cervical vertebral $(\mathrm{C} 1-3)$ and $\mathrm{C} 7-\mathrm{T} 1$; in the meantime, incidences of postoperative neck stiffness and kyphosis were minimized. Our previous study showed that the use of this surgical approach could effectively maintain cervical lordosis after surgery [15]. In this study, although the cervical curvature decreased slightly after surgery, the change was not significant when compared to baseline (pre-surgery). Cervical lordosis was well maintained, and no cases of cervical kyphosis were reported.

Two surgical related complications were commonly seen in posterior cervical surgery, and they were axial pain and $\mathrm{C} 5$ palsy. The incidence rate of axial neck pain after laminoplasty was reported in $6-60 \%$ of patients $[7,18]$, while C5 palsy was reported in $4.8-11 \%$ of patients $[19,20]$. In the current study, the incidence of axial pain was $6.36 \%$, and the incidence of $\mathrm{C} 5$ palsy was $3.64 \%$. The incident rates were similar to those reported, suggesting the use of short segment (C4-6) internal fixation would not increase the complication rate. Importantly, most patients with $\mathrm{C} 5$ palsy recovered within 1 year after surgery. Also, the axial pain was improved during follow-up visits. Overall, the use of short-segment lateral mass screw fixation would not increase neck stiffness, and the range of motion of the upper cervical vertebral $(\mathrm{C} 1-3)$ was well maintained. The neck activities of patients, especially neck rotation, were not affected.

In this study, we also investigated the differences in clinical outcome between unilateral and bilateral fixation. It was appeared that both the unilateral and bilateral fixation had similar effects on improvement of clinical symptoms and maintenance of cervical curvature. There was no report of cervical kyphosis after surgery in both groups. However, it should be noted that some patients were not randomly assigned to unilateral or bilateral fixation. In some cases, operators would

Table 5 Changes of curvature before and after surgery

\begin{tabular}{|c|c|c|c|c|c|c|c|}
\hline & \multicolumn{2}{|c|}{ Unilateral } & \multicolumn{2}{|c|}{ Bilateral } & \multicolumn{2}{|c|}{ All patients } & \multirow[t]{2}{*}{$p^{*}$} \\
\hline & $n$ & Curvature & $n$ & Curvature & $n$ & Curvature & \\
\hline Before surgery & 33 & $14.65 \pm 5.16$ & 77 & $15.39 \pm 5.32$ & 110 & $15.17 \pm 5.26$ & 0.445 \\
\hline Before discharge & 33 & $14.82 \pm 4.01$ & 77 & $14.23 \pm 4.42$ & 110 & $14.41 \pm 4.29$ & 0.934 \\
\hline 6 months post-surgery & 10 & $15.56 \pm 3.49^{a}$ & 19 & $15.78 \pm 5.20$ & 29 & $15.71 \pm 4.62^{c}$ & 0.456 \\
\hline 12 months post-surgery & 17 & $19.78 \pm 8.39^{a}$ & 32 & $21.76 \pm 13.75^{b}$ & 49 & $21.07 \pm 12.11^{c}$ & 0.635 \\
\hline 24 months post-surgery & 5 & $28.46 \pm 3.82^{a}$ & 6 & $28.43 \pm 7.56^{b}$ & 11 & $28.45 \pm 5.87^{c}$ & 0.831 \\
\hline
\end{tabular}

* Comparison between Unilateral and Bilateral; ${ }^{a}$ compared to Unilateral before surgery, $p<0.05 ;{ }^{b}$ compared to Bilateral before surgery, $p<0.05 ;{ }^{c}$ compared to All patients before surgery, $p<0.05$ 


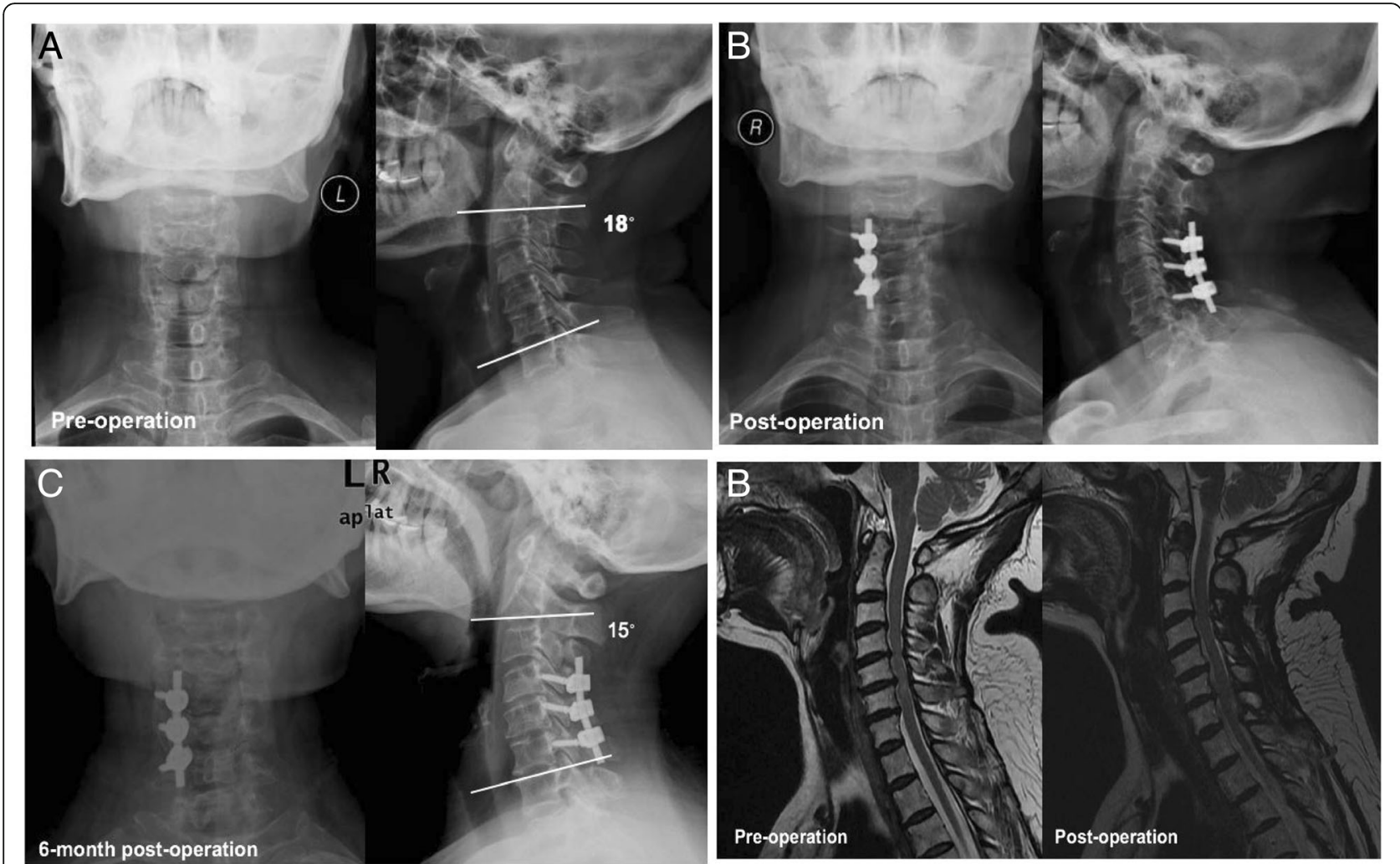

Fig. 1 A representative case in Bilateral Group. a Cervical anterior-posterior X-ray image (left panel) and Cobb's angle (right panel) before operation. b Postoperative anterior-posterior (left panel) and lateral (right panel) X-ray images. c 6-month postoperative anterior-posterior (left panel) and Cobb's angle (right panel) X-ray images. d Preoperative MRI image showing the cord was compressed (left panel). Postoperative MRI image showing the compression of the cord was removed (right panel)

perform bilateral fixation because of the patients' condition (e.g. preoperative lordosis, poor cervical curvature, osteoporosis). In addition, some patients experienced severe bleeding during surgery or had severe hyperplasia. In those cases, only the unilateral approach can be used. The limitation of adequacy to compare the outcomes between the two groups should be realized. In addition, we found inconsistency in the incidence of axial pain and C5 palsy between groups. For example, some centers had a higher incidence of axial pain in Unilateral group, while some centers had a higher incidence of axial pain in Bilateral group. This may due to the overall low incidences of complications, and the sample size was small. In some centers, there was only one case (or even none) of axial pain or C5 palsy. This may have certain impact on the results.

All of the lateral mass screws used in this study were fixed by free hand without using intraoperative imaging, like fluoroscopic control. A study reported that among the 1256 screws fixed using the free hand technique, the incidence of foramen transversarium violation was $0.876 \%$ (mostly in C6), and the incidence of facet violation was $1.433 \%$ [21]. Other studies reported that the poor surgical technique might cause penetration of the screw into the central portion of the transverse foramen, vertebral artery injury, or even brain stem infraction [22, 23]. Other screw fixation associated complications include nerve irritation, fracture of lateral mass, and screw pull-out [24]. In this study, there were no cases of vertebra artery, nerve root, or spinal cord injury. This may be related to the lateral mass screws selected in this study, which were short with length at $14 \mathrm{~mm}$. Also, we did not require to have cortex fixation. There were no cases of screw displacement or loosening after surgery, suggesting the safety and effectiveness of the internal fixation.

\section{Conclusion}

The current study showed that the posterior open-door laminoplasty in combination with C4-6 short segment lateral mass screw fixation and fusion provided satisfactory clinical outcome in patients with CSM. The shortsegment internal fixation could help to maintain the cervical lordosis. Lastly, the unilateral and bilateral fixation appeared to provide similar outcomes, in terms of 

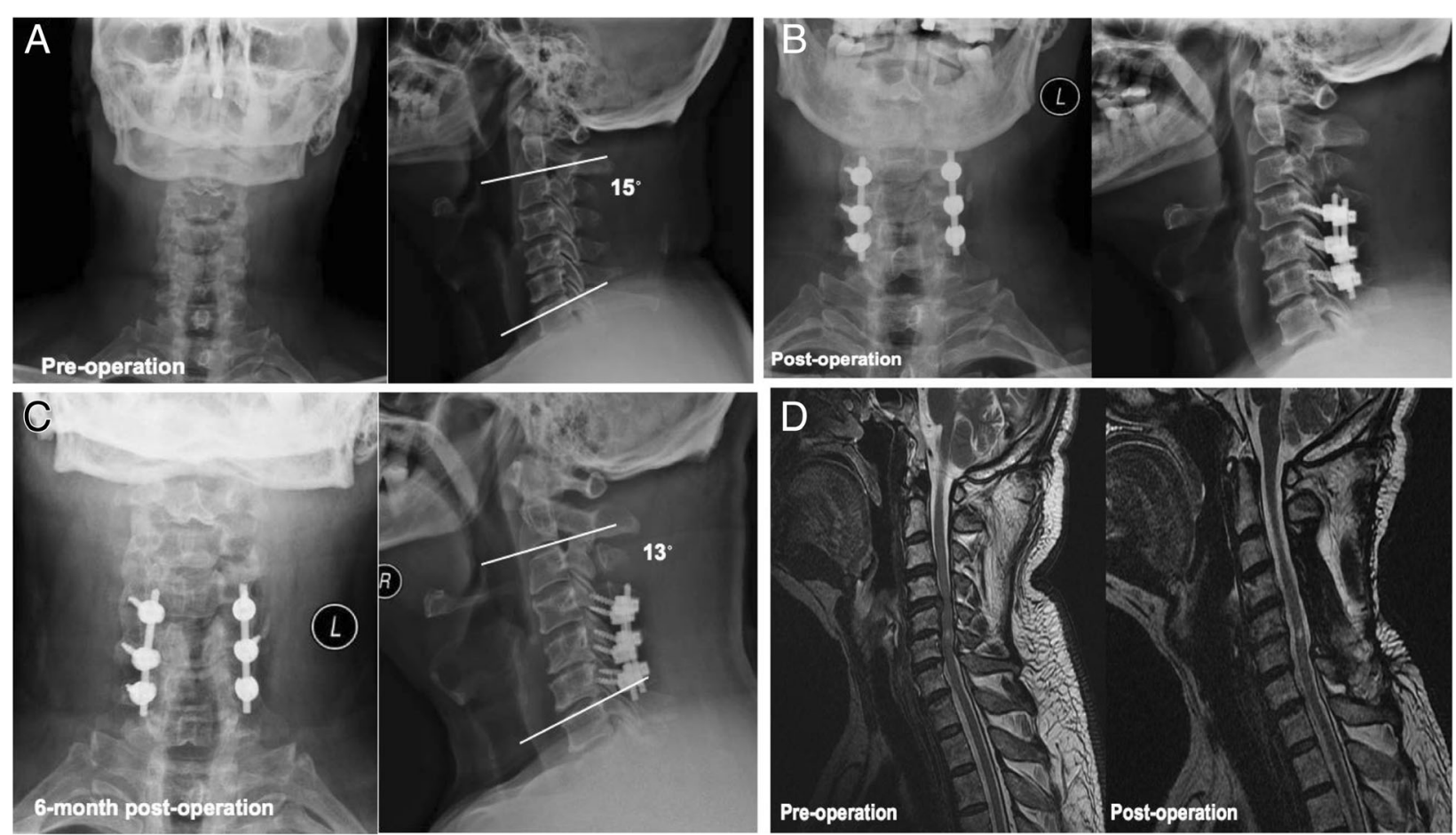

Fig. 2 A representative case in Unilateral Group. a Cervical anterior-posterior X-ray image (left panel) and Cobb's angle (right panel) before operation. b Postoperative anterior-posterior (left panel) and lateral (right panel) X-ray images. c 6-month postoperative anterior-posterior (left panel) and Cobb's angle (right panel) X-ray images. $\mathbf{d}$ Preoperative MRI image showing the cord was compressed (left panel). Postoperative MRI image showing the compression of the cord was removed (right panel)

cervical curvature maintenance and improvement of clinical symptoms. However, it is worth to note that some patients were not randomly assigned to unilateral or bilateral fixation, because of the patients' comorbid condition. The examination of the exact differences between the two fixation methods await further biomechanical studies.

\section{Abbreviations}

CSM: Cervical spondylotic myelopathy; DCS: Developmental canal stenosis; JOA: Japanese Orthopedic Association

\section{Acknowledgements}

None.

\section{Authors' contributions}

NS and QF contributed to the conception and design of the study; BW, NK, QZ contributed to the acquisition of data; HT and DL performed the experiments; $J \mathrm{~L}$ and $\mathrm{YY}$ contributed to the analysis of data; NS wrote the manuscript; All authors reviewed and approved the final version of the manuscript.

\section{Funding}

This study was supported by Beijing Science and Technology Commission Biomedical and Life Science Innovation Cultivation Research (No. Z171100000417053). The funding body had no role in the conception, design, conduction, interpretation, or analysis of the study nor in the approval of the publication.

\section{Availability of data and materials}

The datasets used and analyzed during the current study are available from the corresponding author on reasonable request.
Ethics approval and consent to participate

All procedures performed in studies involving human participants were in accordance with the ethical standards of the Institutional Review Board of Ethics Committee of Beijing Friendship Hospital and with the 1964 Helsinki declaration and its later amendments or comparable ethical standards. Written informed consents to participate were acquired from all patients.

\section{Consent for publication}

Written informed consents for publication were obtained from all participants.

\section{Competing interests}

The authors declare that they have no competing interests.

\section{Author details}

'Department of Orthopaedics, Beijing Friendship Hospital, No. 95 Yongan Road, Xicheng District, Beijing 100050, China. ${ }^{2}$ Department of Orthopaedics, Beijing Chao-Yang Hospital, Beijing, China. ${ }^{3}$ Department of Orthopaedics, Beijing Xuan-Wu Hospital, Beijing, China. ${ }^{4}$ Department of Orthopaedics, Beijing Bo-Ai Hospital, Beijing, China.

Received: 14 May 2019 Accepted: 14 August 2019

Published online: 22 August 2019

\section{References}

1. Klineberg E. Cervical spondylotic myelopathy: a review of the evidence. Orthop Clin North Am. 2010;41(2):193-202.

2. Lad SP, et al. National trends in spinal fusion for cervical spondylotic myelopathy. Surg Neurol. 2009;71(1):66-9; discussion 69.

3. Wu JC, et al. Epidemiology of cervical spondylotic myelopathy and its risk of causing spinal cord injury: a national cohort study. Neurosurg Focus. 2013; 35(1):E10.

4. Zhang JT, et al. Relationship between developmental canal stenosis and surgical results of anterior decompression and fusion in patients with cervical spondylotic myelopathy. BMC Musculoskelet Disord. 2015;16:267. 
5. Bajwa NS, et al. Establishment of parameters for congenital stenosis of the cervical spine: an anatomic descriptive analysis of 1,066 cadaveric specimens. Eur Spine J. 2012;21(12):2467-74.

6. Kawaguchi Y, et al. Minimum 10-year followup after en bloc cervical laminoplasty. Clin Orthop Relat Res. 2003;411:129-39.

7. Sani S, Ratliff JK, Cooper PR. A critical review of cervical laminoplasty. Neurosurg Q. 2004;14(1):5-16.

8. Yeh $\mathrm{KT}$, et al. Modified expansive open-door laminoplasty technique improved postoperative neck pain and cervical range of motion. J Formos Med Assoc. 2015;114(12):1225-32.

9. Takeuchi $\mathrm{K}$, et al. Anatomic study of the semispinalis cervicis for reattachment during laminoplasty. Clin Orthop Relat Res. 2005;436:126-31.

10. Sakaura $\mathrm{H}$, et al. Medium-term outcomes of C3-6 laminoplasty for cervical myelopathy: a prospective study with a minimum 5-year follow-up. Eur Spine J. 2011;20(6):928-33.

11. Sakaura H, et al. C3-6 laminoplasty for cervical spondylotic myelopathy maintains satisfactory long-term surgical outcomes. Glob Spine J. 2014;4(3): $169-74$.

12. Yu HL, et al. Laminoplasty using Twinfix suture anchors to maintain cervical canal expansion. Eur Spine J. 2010;19(10):1795-8.

13. Tung KL, et al. Single-door cervical laminoplasty using titanium miniplates alone. J Orthop Surg. 2015:23(2):174-9.

14. Yeh $\mathrm{KT}$, et al. Expansive open-door laminoplasty secured with titanium miniplates is a good surgical method for multiple-level cervical stenosis. J Orthop Surg Res. 2014;9:49.

15. Su N, et al. Long-term outcomes and prognostic analysis of modified opendoor laminoplasty with lateral mass screw fusion in treatment of cervical spondylotic myelopathy. Ther Clin Risk Manag. 2016;12:1329-37.

16. Hyun SJ, et al. The time course of range of motion loss after cervical laminoplasty: a prospective study with minimum two-year follow-up. Spine. 2009;34(11):1134-9.

17. Suk KS, et al. Sagittal alignment of the cervical spine after the laminoplasty. Spine. 2007;32(23):E656-60.

18. Cho CB, et al. Axial neck pain after cervical laminoplasty. J Korean Neurosurg Soc. 2010:47(2):107-11

19. Nassr $A$, et al. The incidence of $C 5$ palsy after multilevel cervical decompression procedures: a review of 750 consecutive cases. Spine. 2012; 37(3):174-8

20. Nakashima $\mathrm{H}$, et al. Multivariate analysis of $\mathrm{C}-5$ palsy incidence after cervical posterior fusion with instrumentation. J Neurosurg. 2012;17(2):103-10.

21. Kim HS, et al. Safety evaluation of freehand lateral mass screw fixation in the subaxial cervical spine: evaluation of 1256 screws. Spine. 2015;40(1):2-5.

22. Cho KH, et al. Poor surgical technique in cervical plating leading to vertebral artery injury and brain stem infarction--case report. Surg Neurol. 2005;64(3):221-5.

23. Inoue $\mathrm{S}$, et al. Cervical lateral mass screw fixation without fluoroscopic control: analysis of risk factors for complications associated with screw insertion. Arch Orthop Trauma Surg. 2012:132(7):947-53.

24. Katonis $P$, et al. Lateral mass screw complications: analysis of 1662 screws. J Spinal Disord Tech. 2011:24(7):415-20.

\section{Publisher's Note}

Springer Nature remains neutral with regard to jurisdictional claims in published maps and institutional affiliations.

Ready to submit your research? Choose BMC and benefit from:

- fast, convenient online submission

- thorough peer review by experienced researchers in your field

- rapid publication on acceptance

- support for research data, including large and complex data types

- gold Open Access which fosters wider collaboration and increased citations

- maximum visibility for your research: over $100 \mathrm{M}$ website views per year

At $\mathrm{BMC}$, research is always in progress.

Learn more biomedcentral.com/submissions 